\title{
Conflict, Settlement, and the Shadow of the Future*
}

\author{
Michael McBride ${ }^{\dagger}$ \\ Department of Economics \\ University of California, Irvine
}

\author{
Stergios Skaperdas \\ Department of Economics \\ University of California, Irvine
}

This version: May 22, 2009

\begin{abstract}
In many instances of potential violent or non-violent conflict, the future strategic positions of adversaries are very different when there is open conflict than when there is settlement. Then, we show that as the future becomes more important, open conflict becomes more likely than settlement. We discuss the applicability of this finding in war, litigation, and other settings, and test it it in a laboratory experiment. We find that subjects are more likely to engage in risky conflict as the future becomes more important.
\end{abstract}

JEL Classifications: C72, C91, D01, D74.

Keywords: conflict, litigation, property rights, folk theorem.

\footnotetext{
${ }^{*}$ We thank Michelle Garfinkel, Gary Richardson, and seminar participants at Loyola Marymount University, participants in the Economic Science Insitute seminar at Chapman University, attendees at the "Rationality and Conflict" conference at Yale University, and participants at the UC Irvine Theory, History, and Development Seminar for valuable comments. For financial support we are grateful to the Center for the Study of Democracy and the Center for Global Peace and Conflict Studies, both at UC Irvine.

${ }^{\dagger} 3151$ Social Science Plaza, Irvine, CA, 92697-5100, mcbride@uci.edu, sskaperd@uci.edu.
} 
That repeated interaction increases cooperation in conflictual settings is commonly accepted wisdom in economics and other social sciences. In the infinitely repeated prisoners' dilemma, for example, the players could follow the strategy of each cooperating until one of them defects and defecting forever after a single defection. For large enough discount factors, although the inefficient conflictual equilibrium continues to be an equilibrium, these strategies that threaten punishment form an equilibrium that supports cooperation. When the "shadow of the future" (Axelrod 1984) looms large the threat of future conflict can therefore enforce cooperative behavior today and indefinitely. The applications of this idea have been extraordinarily numerous and varied (for an overview, see Mailath and Samuelson, 2006), from examining tacit collusion among firms (Green and Porter, 1984) to exploring the viability of political or economic institutions (Greif, 2006, Richardson and McBride, 2009).

In this paper, however, we argue that many actual conflictual settings, both violent and non-violent, lead to the opposite relationship between the shadow of the future and the likelihood of conflict; that is, as the discount factor increases, conflict becomes more likely. There are two primary features of these settings. First, adversaries cannot write long-term contracts on an "enforcement" variable (e.g., arms) but can sustain short-term cooperation under the threat of conflict. Such cooperation can be thought of as "cold wars" and may involve the expenditure of substantial resources by each party to retain its bargaining position in future interactions. This condition is akin to that of the incomplete-contracts approach to the theory of the firm (see, e.g., Grossman and Hart, 1986), whereby agents cannot write long-term contracts on relationship-specific investments but engage in short-term bargaining. Second, conflict today changes the relative strength of the two parties tomorrow in a way that cooperation does not. For example, the winner of a battle between relative equals might gain more resources, and therefore a strategic advantage, relative to the loser well into the future, whereas a cooperative settlement outcome might retain the relative equality in strength. Similarly, going to court will enhance the property rights of the winner of a legal dispute and diminish those of the loser, while an out-of-court settlement does not change as 
much the relative positions of the litigants.

Although short-term settlements are possible, conflict can occur as an equilibrium outcome despite its cost and risk because it can be an investment in one's future strength. By winning a conflict today, an actor improves her relative strength and reduces the cost of enforcement in the future. In the case that the loser is eliminated entirely after a conflict, the winner pays no enforcement costs in the future. For example, a court decision may establish the property rights of the winner and eliminate the need for the winner to hire costly lawyers in the future, and the winner of a war might not have to pay the costs of a prolonged cold war. The shadow of the future plays a crucial role: a higher discount factor implies a higher valuation on the strategic advantage obtainable only through direct conflict and implies a higher future cost, because of enforcement expenditures, of sustaining the status quo. With sufficiently high discount factors, conflict is the equilibrium.

Elements of our argument can be found in the literature on war. Fearon (1995) first discussed the possibility of this line of thought, and models that make the argument explicit include a finite-horizon model in Garfinkel and Skaperdas (2000) and infinite-horizon models in Powell (2006) and McBride and Skaperdas (2007). ${ }^{1}$ That conflict becomes more likely and peace less likely as the discount factor of the adversaries becomes larger is a robust finding in such settings. ${ }^{2}$ In this paper, we identify the key conditions behind this shadow of the future result, demonstrate that these features are common to both violent and non-violent conflict settings, and, using an original laboratory experiment, present empirical evidence

\footnotetext{
${ }^{1}$ Powell (1993) was the first dynamic model that included similar considerations (and the main comparative static result regarding the "shadow of the future") but did not include the possibility of within-period transfers between adversaries. That is, there is a within-period indivisibility in Powell's model, something that is an analytically distinct reason for conflict. However, there is no reason that Powell's (1993) model could be not be adapted to allow for within-period transfers and still yield conflict as a possible equilibirum outcome. Jackson and Morelli (2008) analyze a dynamic model similar to that of Powell and allow for mixed strategies, with conflict taking place for at least some realizations of mixed-strategy equilibria.

Bester and Konrad (2004) provide alternative variations in terms of the timing about the choice of the enforcement variables, the possibility of settlement, and asymmetries across players.

${ }^{2}$ In addition to the papers mentioned above, Powell (1993), Skaperdas and Syropoulos (1996), and Mehlum and Moene (2007) also show how enforcement costs increase with higher discount factor when there is conflict, even though none of these papers allow for settlement. This effect on enforcement costs provides an analytically distinct reason for conflict that relates to the shadow of the future.
} 
that a longer shadow of the future leads to more conflict in such settings.

We note that peaceful settlements in our setting involve short-term transfers that depend on the relative bargaining positions of the adversaries which, in turn, depend on arming or other enforcement variables that are strategically chosen by each adversary. Such peace may also be characterized as "armed peace", in addition to "cold war," because it applies to interactions among adversaries who cannot trust one another enough to commit to disarmament. It is distinguished from complete disarmament (i.e., full cooperation), which could potentially be achieved with enforceable long-term contracts on arms or some other means. We note, however, that complete disarmament is very difficult to achieve in practice and is not the type of peace that has typically prevailed for much of history. ${ }^{3}$ The decision between a bargained armed peace and open conflict, which forms the focus of our paper, is thus empirically relevant and conceptually distinct from universal peace with disarmament.

That conflict is more likely with higher discount factors stands in contrast, though not in contradiction, to the standard intuition from folk theorem arguments. The different effects of the shadow of the future reflect different mechanisms and environments. First, disarmament sustained by history-dependent strategies will not exist in our setting when a loser, whose ability to challenge the winner is eliminated in future rounds, cannot punish the winner in those future rounds. Thus, the threats that enforce peace or cooperation in many well-studied settings will not necessarily produce peace in our setting. Second, if disarmament equilibria supported by supergame strategies were to exist in the non-stationary environments that we examine, they are likely to coexist with the conflict equilibrium for at least some range of discount factors. Which type of equilibrium might be selected in such cases is of course of both theoretical and empirical interest, but the presumption that a higher discount factor would unambiguously favor peace is no longer tenable in view of our findings. ${ }^{4}$

\footnotetext{
${ }^{3}$ Other than statelets like Andorra or San Marino, it would be difficult to find either historical or contemporary examples of states that are completely disarmed. Today, there are very few countries that devote less that $1 \%$ of their GDP to military expenditures, with the average for 2007 hovering around $2.5 \%$ of GDP (see SIPRI, 2008, p.10).

${ }^{4}$ Note that the supergame strategies supporting the more efficient equilibria are more computationally complex and often non-renegotiation proof, something that the simple strategies that implement conflict are
} 
In addition to identifying a different effect of the shadow of the future, our approach provides an explanation of the causes of conflict that complements existing explanations. From warfare to strikes and lockouts to courtroom litigation, conflict in both violent and nonviolent forms is quite common and has considerable economic consequences. ${ }^{5}$ The economics literature has largely focused on the incomplete or asymmetric information of one party about the preferences, endowments, available strategies, or other characteristics of another party as a cause for conflict. (See, for example, Brito and Intriligator, 1985, and Bester and Warneryd, 2006. ${ }^{6}$ Asymmetric information is undoubtedly relevant in many instances of conflict, yet there is scope for additional explanations that do not rely on informational differences among competing parties.

After elaborating on the empirical relevance of our argument in section I, section II develops an illustrative model on which our experiment is based. The model yields the key prediction that conflict is the equilibrium outcome when discount factors are higher than a critical level. Particular extensions and elaborations of the model, provided in the Appendix, illustrate how the main prediction is robust to changes in the adversaries' environment and the particular types of conflict they face. In Appendix A we endogenize the enforcement choices (e.g., arming) of each side, and in Appendix B we examine the interaction of longrun agent against a series of short-run challengers that applies to certain litigation settings. Section III discusses the experiment design and results. Our subjects faced a choice between a certain payoff from settlement or the uncertain outcome of a conflict. The shadow of the

not. On the basis of simplicity and robustness, then, if there should be a presumption in favor of one of the two types of equilibria whenever both exist, the conflictual equilibrium would be selected.

${ }^{5}$ Civil wars, for instance, have severely hampered economic development in a large number of countries during the post-war period (Collier et. al., 2003, and Blattman and Miguel, 2009). Blomberg and Hess (2008) estimate that worldwide the overall cost of conflict has been about 9 percent of steady-state consumption, with some countries that have experienced protracted conflict having much higher costs. Less violent forms of conflict are also relevant to economic activity; going to court is a rather common phenomenon whereas strikes and lockouts have been less common in the U.S over the past few decades but still common in other countries.

${ }^{6}$ Other reasons, based on economic models, that may induce conflict include indivisibilities, increasing returns in production, risk seeking preferences. For a review of reason for going to war primarily concernced with international relations see Fearon (1995) and for a review based on conflict models that allow for bargaining see Skaperdas (2006). 
future is approximated by a constant continuation probability of the game. In this last feature of the experiment we have followed Dal Bó (2005), who has examined the effects of the shadow of the future in stationary environments in which the folk theorem applies. ${ }^{7}$ We find a clear tendency for a longer shadow of the future to increase the subjects' choice of conflict, especially compared to the one-shot case with zero continuation probability.

\section{Going to Court, Engaging in War, and Other Con- flictual Settings}

The two aspects of the environments that we examine in this paper are (i) the impossibility of writing long-term contracts on enforcement levels and (ii) conflict and settlement have very different paths in terms of the initial conditions that adversaries face in the future. Condition (i) is very likely to be satisfied both in adversarial settings that can lead to war and in legal disputes. The main enforcement variable in wars is arming, and in many cases it is impossible to write long-term disarmament contracts (although, it is typically possible as well as a frequent occurrence to have truces and cold wars - thought of as a series of short-term contracts - that are enforceable by each adversary's military strength). In legal disputes the main enforcement variable involves litigation expenditures on lawyers, paralegals, private investigators, or potential expert witnesses, and it is similarly difficult to write long-term contracts that would prevent potential legal adversaries from engaging in any such expenditures. However, the retention of lawyers and the threat to deploy them in court could help enforce shorter-term out-of-court settlements.

We next discuss why condition (ii) is plausible in many circumstances and why the type

\footnotetext{
${ }^{7}$ The only other experimental study that we know that considers conflict and settlement in a dynamic environment is Tingley (2009), whose experiment was conducted independently of ours. Tingley tests Fearon's (1995) idea about the effect of declining bargaining power on the incidence of conflict. Both the theoretical and experimental findings about the shadown of the future are similar to our, though the mechanism behind the findings and experimental design are different from ours. The ultimate reason for conflict in Fearon's model is the presence of bounds on transfers, a restriction which we do not assume.

In other experimental work on conflict, Durham, Hirshleifer, and Smith (1996) provide evidence of a static model of conflict like that of Hirshleifer (1991) which is also similar to a stage game of the dynamic model in Appendix A. Abbink and Brandts (2009) study experimentally the choice between conflict and settlement in a static setting when settlement is always efficient.
} 
of explanation we examine in this paper is promising for understanding a wide variety of conflicts.

\section{A Legal Disputes}

As is the case with wars, information problems are considered the primary reason for legal disputes ending up in court (see, for example, Hay and Spier, 1998). However, going to court and settling out of court can have significantly different implications for the relative future strategic positions of potential litigants.

On the one hand, going to court enhances the strategic position of the winner and increases his chance of prevailing in similar future disputes with the same or different adversaries. Conversely, the loser has a diminished future strategic position to prevail in similar disputes. In other words, going to court and obtaining a decision enhances the property rights of the winner and diminishes those of the loser well into the future.

On the other hand, settling out of court tends to leave the relative property rights positions of adversaries in the future more stable, though not necessarily constant. Settling out of court with someone who has sued you could invite future litigants who might sue you solely in order to extract an out-of-court settlement. Therefore, going to court, though costly in the short-run, could deter future litigation and the costs that would accompany such litigation. Moreover, in many legal systems the holder of an asset who does not period-

ically exercise some form of open demonstration of ownership, including possibly receiving a positive court decision, could lead to the loss of the asset or at least the "atrophying" of his or her property right over that asset (Buchanan, 1989).

Thus, going to court enhances property rights whereas not doing so might erode one's property right. Indeed, going to court can be an equilibrium outcome, even in the absence of any informational problems, when it is necessary to ensure future property rights.

Our modeling approach, wherein potential litigants make choices on legal expenditures that determine each side's probability of winning in court, follows Farmer and Pecorino 
(1999) and Hirshleifer and Osborne (2001). Robson and Skaperdas (2008) further distinguish between going to court and settling out court, and show how going to court can be an equilibrium in finite-horizon interactions.

\section{B Wars}

For disputes that could potentially lead to war it is evident that war affects the adversaries' future strategic positions differently than does a truce or peace. Winners can obtain a better future strategic position that they had prior to war, and losers typically have a worse strategic position than prior to war. In the absence of war, strategic positions do not change as much, although one side's power may be declining over time while the other side's power might be ascending because of economic, demographic, or other reasons.

Clearly, informational problems can help explain many wars. However, there is no reason to think that all wars in all of their aspects must be due solely to such problems. We briefly offer some examples in which our hypothesis is relevant and identify some examples of warfare that are difficult to explain with informational failures.

Since the Second World War, civil wars have been much more common than interstate wars. With an average duration of over seven years (Collier et. al., 2003), by that time both informational asymmetries and the costs of war become apparent. Similarly, civil wars within Northern Italian city-states in late medieval times often lasted for decades with tremendous costs to the participants (see, for the case of Genoa, Ch.8 in Greif, 2006). Before attributing all such conflicts to informational problems, the gamble on gaining long-term advantage over opponents appears as at least another, complementary to others, explanation of the many civil wars that have occurred. Moreover, in many cases it can be argued that many key participants in ethnic and religious conflict tend to value the future highly, because of their close identification with the future of their ethnic group or with religious salvation, and thus contribute to the intensification of conflicts and the difficulties in achieving peaceful settlements. 
World War I is frequently mentioned as a war that started because of information problems (see, for example, Ch. 2 in Joll, 1992). Incompleteness of information might not be the whole story, however, if we were to consider that there was no peace after it became obvious to almost everyone that trench warfare brought stalemate and not quick victory. With trench warfare much of the initial incomplete information dissipated, the costs of the war continuing were horrendous with no end in sight, and yet war continued. Reasonably, it could be argued that each side saw the chance of eventual dominance well into the future as the carrot that kept the war going, and that all major adversaries had long-term strategic objectives that made them arm in the first place. At least some fraction of the elites within each of the major states involved saw a war as necessary for the defense of existing possessions or repossession of old ones close to them (like Alsace and Lorraine for France and Germany) or for the defense or capture of areas around the globe.

Also, relevant to our approach was the endgame of World War II. Why didn't the United States settle for the advantageous peace for which Japan was bidding? Why did the Soviet Union push so hard, and at such cost, in the Eastern front? Why were the Western allies rushing in the Western front? Certainly it could not be because they were not aware of Japan's or Germany's strength or the other way around. The allies were all looking into the future. They wanted the Axis powers crushed without the possibility of even a remote comeback, as it happened with Germany after World War I. They were also eyeing one another, jockeying for position in the post-war period. The Cold War had effectively started considerably before the end of the actual hot war.

\section{Other Types of Conflict}

In addition to warfare and litigation, there are other types of disputes that could be relevant for the approach we develop here. They include rent-seeking and related policy disputes, labor union and firm disputes, and possibly competition among firms that use marketing and advertising as major instruments of competition. For the case of rent-seeking and other 
policy disputes, the relevant enforcement variables are expenditures on lobbying and related activities that are clearly not contractible in the long-run. Settlement in this case would imply that the major sides to the policy dispute agree on a compromise proposal, whereas conflict would involve each side offering clearly different proposals, not compromising, and letting the lobbying and legislative process determine which proposal is eventually adopted.

For the case of disputes between labor unions and firms, the non-contractible variables would include the expenditures on the part of the union on strike preparation (including possibly the accumulation of a strike fund) and for the firms the resources expended on negotiation and preparations for a strike or a lockout. Conflict in this case would involve a strike or a lockout, whereas settlement would involve the signing of a new contract for a set period of time. For the case of competing firms, the non-contractible enforcement variable could be the resources expended on marketing and advertising, whereas conflict would be equivalent to a price war and settlement a more cooperative outcome on their part. In all these cases, the conflictual and settlement outcomes can bring about different future strategic positions for the adversaries, and therefore our approach and the effect of the shadow of the future can be important for bringing about conflict or settlement. However, we do not pursue these applications further as the literature and applications do not appear to our knowledge to be as developed as for applications to litigation and warfare.

\section{An Illustrative Model: Conflict vs. Settlement}

Consider two agents, $A$ and $B$, who interact over an indefinite horizon. In each period they compete over a prize of value $Y$. Because the two agents cannot write contracts on the ultimate source of enforcement each period they have to expend resources $e_{A}$ and $e_{B}$ to maintain their position. These expenditures are necessary regardless of whether Conflict or Settlement (under the threat of conflict) ultimately prevails. In the case that Conflict involves actual warfare, $e_{A}$ and $e_{B}$ would represent arming expenditures, and the two agents could be parties in a domestic dispute that could lead to civil war or adversarial states. In 
the case of litigation $e_{A}$ and $e_{B}$ would represent expenditures on lawyers' and related fees, and the two agents could be two parties that have property claims on a productive asset which they could exploit jointly without going to court or they could go to court and resolve their claims once and for all. (In Appendix B, we examine another model of litigation that involves a long-term agent who faces the potential of being sued for damages in each period by a series of short-term agents.)

In the event of Conflict, the enforcement expenditures $e_{A}$ and $e_{B}$ affect the probabilities of winning for each side; we denote these probabilities by $q_{A}$ and $q_{B}$. We suppose that one agent's enforcement expenditures positively affect his own winning probability and negatively affect his opponent's winning probability. As our experiments do not involve an endogenous choice of these expenditures, we do not endogenize them here, although as we show in Appendix A that the main comparative static results are, if anything, strengthened when enforcement expenditures are chosen endogenously. Models of conflict that examine the endogenous determination of arming in static settings include Hirshleifer (1991) and Esteban and Ray $(1999,2008)$, whereas models dedicated to litigation have been examined by Farmer and Pecorino (1999) and Hirshleifer and Osborne (2001). In the case of Settlement, $e_{A}$ and $e_{B}-$ through their effect on the probabilities of winning in the event of Conflict - influence each agent's bargaining position in arriving at a particular deterministic settlement (shares of the prize $Y)$.

If Conflict were to take place only a fraction $\phi \in(0,1)$ of $Y$ can be consumed with the rest, $(1-\phi) Y$, being destroyed by the conflict. In each period, then, the expected single-period payoff of agent $i=A, B$ in the event of Conflict is

$$
U_{i}^{c}=q_{i} \phi Y-e_{i}
$$

Given that Conflict is destructive, in each period both sides would prefer to divide $Y$ in shares that equal their winning probabilities because it would result in a payoff of $q_{i} Y-e_{i}>$ $q_{i} \phi Y-e_{i}=U_{i}^{c}$. A range of other possible divisions of $Y$ would also be Pareto superior to the expected payoffs under Conflict. With an indefinite repetition of such single-period 
interactions, there would never be an incentive to induce Conflict, provided the two agents could costlessly communicate and the prize $Y$ were divisible.

Nevertheless, if Conflict were to occur, we would reasonably expect interactions between the two agents to be different in the future. The winner may have eliminated the loser's ability to carry out war in the future, or he could command more resources conducive to waging war than the loser in the future. In effect, conflict biases future conflicts even further in favor of today's winner. Such induced asymmetries could well make Conflict an attractive possibility by trading off a lower expected payoff today for higher payoffs in the future.

For simplicity, we allow a stark and simple form of dependence of future power on today's Conflict. We suppose that the loser of Conflict in any period would be unable to raise the resources that are necessary to challenge the winner in future periods and, thus, the winner would be able to enjoy the prize $Y$ in all future periods whereas the loser receives nothing. (McBride and Skaperdas, 2007, illustrate how the main results extend to the less stark setting in which for an agent to drop completely out of contention there is a series of small conflicts with probabilistic outcomes, and not just one, that would have to be lost.)

Next, consider the negotiations that would result in either Settlement or Conflict in any particular period in which no Conflict has occurred in the past and the agents have already expended resources on enforcement (i.e., e's have been expended and represent sunk costs). Further, and without loss of generality, suppose agent $A$ is the one that has the initiative in making a proposal. (Other protocols of moves, including the sharing of the potential gains of settlement which we follow in the experiments, would not change the parameter values under which Conflict and Settlement would take place.) In the case of Settlement, the agent would receive the whole value of $Y$ and would make an offer of subsidy $S$ to agent $B$, which would either accept or reject $A$ 's offer. If the offer is rejected, Conflict ensues. The resources that each party has invested on enforcement are considered sunk so that they play no more in current negotiations. 
Assuming a discount factor $p \in(0,1),{ }^{8}$ the discounted expected payoff for agent $i=A, B$ in the event of Conflict is the following:

$$
V_{i}^{C}=q_{i} \phi Y+q_{i} \sum_{t=1}^{\infty} p^{t} Y+\left(1-q_{i}\right) \sum_{t=1}^{\infty} p^{t} 0=q_{i}\left(\phi+\frac{p}{1-p}\right) Y
$$

Note how in the event of Conflict, because one agent would be eliminated from contention, in the future no resources would be devoted to enforcement. Agent $B$ would accept any offer $S$ from agent $A$ that satisfies inequality

$$
S+p V_{B}(S) \geq V_{B}^{C}
$$

where $V_{B}(S)$ denotes the continuation payoff of agent $B$ when she is a responder given the subsidy $S$. As part of any Markov Perfect Equilibrium in which a positive subsidy is given, agent $A$ would offer a subsidy $S^{*}$ that satisfies (3) as an equality. Assuming that $S^{*}$ would be accepted in this period, it would be acceptable in all future periods and therefore $V_{B}\left(S^{*}\right)=\frac{S^{*}-e_{B}}{1-p}$. Then, from (3) and (2), the subsidy would be

$$
S^{*}=q_{B}[\phi(1-p)+p] Y+p e_{B}
$$

Note that this Conflict-deterring subsidy from $A$ to $B$ depends positively on the power of agent $B$ (as proxied by her probability of winning $q_{B}$ ), on the share of output that is not destroyed in the event of Conflict, on the discount factor, as well as on the value of the prize $Y$. However, this minimally acceptable subsidy to agent $B$ might not be in agent $A$ 's interest to offer. In particular, agent $A$ will only make this offer if the expected payoff under Settlement exceeds that under Conflict,

$$
Y-S^{*}+p V_{A}\left(S^{*}\right) \geq V_{A}^{C}
$$

where $V_{A}\left(S^{*}\right)=\frac{Y-S^{*}-e_{A}}{1-p}$ is the continuation payoff of agent $A$ if Settlement were to prevail forever. Supposing the probabilities of winning for the two sides sum to one (i.e. $q_{A}+q_{B}=1$ ),

\footnotetext{
${ }^{8}$ Given risk neutrality, could also be interpreted as the constant probability of the game continuing in each period, an interpretation that we maintain in the experiments.
} 
it is straightforward to show that the condition for Settlement (so that (3) and (5) are both satisfied) is as follows:

$$
\frac{p\left(e_{A}+e_{B}\right)}{(1-\phi)(1-p)} \leq Y
$$

If this inequality holds, there is a feasible and optimal subsidy that makes Settlement preferred to Conflict. Alternatively, based on (6), Conflict is more likely and Settlement is less likely, the lower is the contested output $Y$; the higher are the resources devoted to arming $\left(e_{A}+e_{B}\right)$ by the two agents; the less destructive is Conflict (or, the higher is $\phi$ ); and, the higher is the discount factor $p$ (i.e., the game's constant continuation probability). In terms of the main variable of interested, for any combination of the other parameters such that

$$
p>p^{*}=\frac{Y(1-\phi)}{e_{A}+e_{B}+Y(1-\phi)},
$$

then the equilibrium outcome is Conflict.

It is this last effect of the "shadow of the future" that we test experimentally. In Appendix $A$ and $B$ we show the robustness of this effect in different settings. In Appendix A, we endogenize the enforcement efforts $e_{A}$ and $e_{B}$. In Appendix B, we provide a model of a legal dispute involving a long-term agent against a series of short-term agents who could potentially sue the long-term agent for damages.

\section{An Experiment: Conflict vs. Settlement}

\section{A Experimental Design}

Our experiment consists of three sessions conducted at the California Social Science Experimental (CASSEL) Laboratory at UCLA. Each session used subjects recruited from the CASSEL subject pool database. After learning about the laboratory from advertisements or friends, a UCLA student registers in the subject pool through the laboratory's web site. All subjects in the pool were sent an email notifying them of an experiment session. An interested student then registers for a specific sessions; none participated in more than one session. 
To facilitate experiment management, instruction, and data collection, we conducted the experiment using specially designed software. Each subject accumulated "points" based on her choices, the choices made by her matched partner in a given round, and random draws by the computer. The more points earned, the more U.S. currency the subject received at the experiment session's end, with the exact amount determined by a publicly announce point-dollar exchange rate. Each subject also received a $\$ 5$ show-up payment. The average earned amount was $\$ 30$ for about 75 minutes of participation.

A Single Match. A single session consists of a number of matches (trials). Each match captures the reduced Settlement-or-Conflict decision scenario depicted in the model, the only difference being that, instead of having subjects choose the settlement amount as in the model above, we suppose Settlement involves an equal split of the surplus. The main comparative statics of the model are unchanged with this simpler exogenous Settlement amount, and this set-up is easier for subjects to understand.

In a single match, two subjects are paired and round one begins. Neutral language is used to mitigate framing effects. Both are publicly told that the "point value" is 100 (prize $Y$ in Section 3's notation), the "standard fee" is 30 (arming cost $e=e_{A}=e_{B}=30$ ), the "flipping fee" is 30 (total destruction $(1-\phi) Y$ ), and the "continuation probability" (probability $p$ ) which takes one of three values (see below). Each subject then selects either "split" (Settlement) or "flip" (Conflict). Payments are then received according to the model presented earlier. That is, in round 1 each receives $20\left(=\frac{1}{2} Y-e\right)$ if both chose split; and if at least one chose flip, then a random draw by the computer selects one of the subjects to be the winner and the other to be the loser, where the winner's round 1 payment is 40 $(=\phi Y-e)$ and the loser's round 1 payment is $-30(=-e)$. The computer then randomly determines whether the match continues to round 2 . If both chose split in round 1 , then the round 1 settlement applies to any future rounds. Thus, should round 2 be reached, settlement in round 1 implies settlement in round 2 , and each receives 20 . If there was conflict in round 1 , then the winner from round 1 receives 100 in round 2 , and the loser in 
round 1 receives 0 in round 2. Any other future rounds, should they be reached, have the same payoff structure as round 2. Having each subject only make one choice per match (rather than making a choice in each round following peace) simplifies the decision process for the subjects, speeds up the experiment, and facilitates the making of hypotheses (see below).

Continuation Probability. The continuation probability $p$ is the key treatment variable as it reflects the shadow of the future. It takes one of three values: $0,0.5$, or 0.75 . A match lasts a single round if $p=0$. If $p=0.5$ or $p=0.75$, then the exact number of rounds in a given match is determined randomly by the computer. The expected number of rounds is 2 under $p=0.5$ and 4 under $p=0.75$. Subjects are told the continuation probability at the same time they are told the other parameters - immediately prior to making the split-or-flip (Settlement-or-Conflict) decision. These values for $p$ were selected because, first, they are the same used by Dal Bó (2005), thereby providing a point of comparison with his study, and, second, they allow for sharp predictions as discussed below.

Rotation Matching. Dal Bó (2005) uses a rotation matching procedure "to avoid potential interaction and contagion effects between the different" matches (1596). In each session, subjects are divided into two equally-sized groups of agents: Blue and Red. In any given match, a Blue and Red are paired. In the next match, the Blue is matched with a different Red, and so on. One full rotation (also called a zipper) consists of each blue being paired exactly once with each Red. With 24 subjects split into Blue and Red groups each with 12 subjects, one rotation consists of 12 matches. With three treatment values for the continuation probability, we thus have 4 matches per treatment variable in one rotation. We use Dal Bó's rotation mechanism primarily for comparison with Dal Bó's design even though the contagion effects that might arise in his repeated game context are unlikely to be present in our setting. Contrary to the mixed-motive prisoner's dilemma game, the weakly dominant strategy in our setting yields the highest expected payoff ex ante, thus removing the incentive to play meta-strategies across matches. 
Sessions. We conducted three sessions to consider how changes in the treatment variable may impact decisions. Session 1 uses one matching rotation (12 matches) with an ABC design: 4 matches of $p=0$, then 4 matches of $p=0.5$, and then 4 matches of $p=0.75$. We supposed that this order would be easiest for subjects. Session 2 uses one rotation with a CBA design: 4 matches of $p=0.75$, then 4 matches of $p=0.5$, and then 4 matches of $p=0$. The reverse order is meant to capture a priming effect. Session 3 uses two full rotations (24 matches) with an ABCCBA design: subjects do one full rotation akin to Session 1, are then reagented into Blues and Reds, and then do another full rotation akin to Session 2. Session 3 is meant to capture both the learning and priming effects. Table 1 summarizes basic information about the three sessions. The bottom panel of the table breaks Session 3 into its first and second matching rotations and calls them Sessions 3(a) and 3(b).

Instructions. After being seated at computers in the lab, the subjects were instructed in the basic payoff structure of the decision making environment, and then they participated

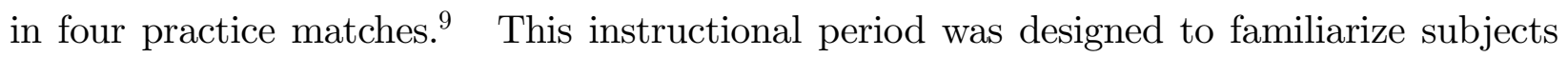
with both the computer user interface as well as the payoff structure and basic strategic environment.

Bankruptcy Prevention. Because losing a contest involves a net loss of 30 points, it is possible for subjects to lose points throughout the experiment. To prevent bankruptcy and the risk-loving behavior that may accompany it, each subject in Sessions 1 and 2 was given an initial 240 points. Because subjects in Session 3 participated in two matching rotations, they were given 240 points twice, once at the start of each rotation. No subject in any session experienced or came close to bankruptcy.

Questionnaire. After the last match but before leaving the laboratory, each subject filled out a questionnaire that asked for age, sex, major, year in school, number of economics courses taken, number of statistics courses taken, and so on. We use information from the

\footnotetext{
${ }^{9}$ In the first practice match, the continuation probability was $p=0$, and each subject was told to select split. In the second practice match, the continuation probability was again $p=0$, but each Blue was told to select split while each Red was told to select flip. The third and fourth practice matches had $p=0.5$ and $p=\frac{3}{4}$, respectively, and subjects were asked to choose split or flip on their own.
} 
questionnaire for rough qualitative comparisons of the subjects across sessions. ${ }^{1011}$

\section{B Hypotheses}

Having one choice per match collapses the potentially infinitely repeated game, in expected payoff terms, into a simple $2 \times 2$ matrix normal form game. Figure $1(\mathrm{a})$-(c) presents the matrix for each treatment value of the continuation probability. In each case, the setting is the Hi-Lo game depicted in Figure 1(d). If the expected payoff when both choose split, $\frac{1}{1-p}\left(\frac{1}{2} Y-e\right)=\frac{20}{1-p} \equiv x$, is strictly greater than that when at least one flip is chosen, $\frac{1}{2}\left(\frac{1}{1-p} Y-(1-\phi) Y\right)-e=\frac{1}{2}\left(\frac{100}{1-p}-30\right)-30 \equiv z$, then each player has a unique weakly dominant strategy to choose split when $p<p^{*}=\frac{1}{3}$ and choose flip when $p>p^{*}=\frac{1}{3}$. Though each game in Figure 1 has multiple Nash equilibria, applying standard game theoretic solution concepts (dominance solvability or Trembling Hand Perfection) yields an unique prediction of (split,split) under $p=0$ and (flip,flip) under $p=0.5$ or $p=0.75 .{ }^{12}$ Past experimental work also suggests that subjects overwhelmingly go for the higher expected payoff in Hi-Lo games (e.g., see Bacharach 2006). Our first hypothesis follows.

\section{Hypothesis 1 (Choices)}

(a) We will observe more flips under $p=0.75$ than under $p=0$.

(b) We will observe more flips under $p=0.5$ than under $p=0$.

Our second hypothesis focuses on outcomes not individual choices, though the former are clearly derived from the later.

\section{Hypothesis 2 (Outcomes)}

(a) We will observe more conflict under $p=0.75$ than under $p=0$.

\footnotetext{
${ }^{10}$ A supplemental appendix with instructions and questionnaire is available from the authors upon request.

${ }^{11}$ Our experiment differs from Tingley (2009) in the various ways, including the following. First, the winning probabilities differ in round 1 from any other future periods. Second, there is no cost of arming in Tingley. Third, in each period the players engage in an ultimatum game.

${ }^{12}$ With $p=0$, there are two pure strategy Nash equilibria: (split,split) and (flip,flip). With $p=0.5$ or $p=0.75$, there are three pure Nash equilibria: (flip,flip), (flip,split), and (split,flip). However, there is only one pure Nash equilibrium in each case if we eliminate the weakly dominated strategy for each player.
} 
(b) We will observe more conflict under $p=0.5$ than under $p=0$.

We are also interested observing the patterns of choices by individual. Given Hypothesis 1 , we predict the following.

Hypothesis 3 (Choices by subject) Most subjects will choose more flips under $p=0.75$ than under $p=0$ and more flips under $p=0.5$ than under $p=0$.

The first two hypotheses test the effect of the shadow of the future on Conflict. Given the structure of the interaction, it is natural to suppose each subject follows a cut-off rule with respect to $p$ when deciding to Settle or Fight. We are less interested in where this cut-off is for each subject, as it may differ from subject to subject due to variation risk preferences or other considerations, and more interested in whether or not the subjects are following such a cut-off rule. For this reason, we selected two values of the treatment variable to yield clear predictions via a clear payoff dominance (split under $p=0$ and flip under $p=0.75$ ). The other value, $p=0.5$, yields flipping under risk neutrality but might yield splitting under $p=0.5$ if subjects have sufficient risk aversion. Bearing this mind, we make no explicit hypothesis about the frequency of flips under $p=0.5$ compared to under $p=0.75$.

The last hypothesis is meant to "unpack" any verification or rejection of the first hypothesis. By looking more closely at the choices by individual we can discern what other factors, if any, figure prominently in the subjects' decision making. We also note that all hypotheses are falsifiable using standard statistical tests.

\section{Results}

Individual Choices. Table 2 reports the percent of flips by session and continuation probability. When pooling the data from all sessions, we see that, consistent with Hypothesis 1 , subjects choose flip more often under $p=0.75$ than under $p=0$ and more often under

$p=0.5$ than under $p=0$. We conducted a series of (Pearson) Chi-square tests to test if the proportion of flips are the same under two given treatment values for $p$. As shown in Table 
3 , we reject at very high significance levels the hypothesis that the proportion under $p=0$ and $p=0.75$ and under $p=0$ and $p=0.5$ are equal. Similar patterns are observed when looking at the data by session. Flips are more frequent in a statistically significant manner under $p=0.75$ and $p=0.5$ than under $p=0$.

We observe that the percent of flips under $p=0.5$ and $p=0.75$ are similar in the pooled data but with some variation across the sessions. While more flips occur under $p=0.75$ than $p=0.5$ in Session 1, the percent flips is nearly identical under those two treatment values in Sessions 2 and 3. The final column in Table 3 reports that the difference in flips is statistically significant in Session 1 but not in Sessions 2 and 3. Again, we note that this could be due to variation in subjects' risk preferences, with subjects in Session 1 exhibiting more risk aversion, on average, than those in Sessions 2 and 3.

Figure 2 displays the percent flips by match for each session. Each point captures the percent of subjects who chose flip in a given match and session. Matches have been grouped by continuation probability to facilitate comprehension. In each session, we observe a dramatic rise or drop in flips as the continuation probability changes from or to 0 , consistent with our shadow of the future argument.

The overall picture is that Hypotheses 1 is strongly confirmed: increasing the shadow of the future does increase the incidence of conflict. This pattern is observed when the data are pooled and when the data are separated by session. There is also some evidence that risk aversion may factor into some subjects' decision, especially for values of $p$ that are greater than but close to $p^{*}$. Another interpretation is that the direction of changes in the treatment variable produces confounding effects. For example, subjects in Session 1 proceeded in what we consider the easiest format, experiencing $p=0$ first and then experiencing "natural" increases in $p$; subjects in Session 2 proceeded in the more difficult format of highest $p$ first; and subjects in Session 3 proceeded in a combination structure that was not natural for learning.

Outcomes. Table 4 reports the distribution of outcomes by session and continuation 
probability. The easiest way to understand the table is to look at the percent of split-split outcomes; this outcome corresponds to Settlement while the other two outcomes correspond to Conflict. Consistent with Hypotheses 2, in the pooled data we observe the occurrence of Settlement to be lower under $p=0.75$ and $p=0.5$ than under $p=0$. The same pattern holds when looking by session, and it also matches that of individual choices. Chi-square tests (not shown) confirm the pattern. Conflict is much more likely when the shadow of the future is large ( $p=0.5$ or $p=0.75)$ than when it is small $(p=0)$.

Choice Patterns. To evaluate Hypothesis 3, we classified subjects by their observed choices as reported in Table 5. The columns partition the behavior into disjoint choice patterns. Column (1) corresponds to the selection of flip in all matches of the session, column (2) corresponds to the selection of split in all matches, and so on. Columns (4) and (5), which are in bold lettering, correspond to the choice pattern predicted by Hypothesis 3. Column (4) is the strict variant such that all subjects included here chose strictly more flips under $p=0.75$ and $p=0.5$ than under $p=0$, while column (5) includes subjects who did not choose strictly more for both but did choose weakly more for both. The most common choice pattern corresponds to the behavior predicted in Hypothesis 3. By the strict measure, $54 \%$ (39 out of 72) of the subjects chose as predicted; by the weaker measure (combining columns (4) and (5)), the number increases to $65 \%$ (47 of 72). This choice pattern is also modal within each session, with roughly the same frequencies, i.., the predicted pattern accounts for more than half in each session (not shown). Moreover, as shown in Table 5, it is also the modal behavior for various subsamples by characteristic: male or female, undergraduate or graduate, exposed to economics or statistics or not exposed.

We observe a wide variation in choice behavior among the other subjects. For example, some $6 \%$ of all subjects ( 4 of 72 ) flipped most under $p=0,7 \%$ (5 of 72 ) never flipped, and 4\% (3 of 72) always flipped. The distribution of choice patterns is also similar across sessions (not shown). The various choice patterns may reflect preferences for risk, equity, 
or some combination of these or other concerns. ${ }^{13}$ Another possibility is that these other choice patterns reflect misunderstanding the decision making environment. Ruling this out is not possible, yet we gain some insight from the last question of the questionnaire, which asked, "Were you more likely or less likely to select FLIP as the continuation probability increased? Why or why not?" $72 \%$ (52 of 72 , line J column 10) of the subjects answered yes and provided some explanation why (e.g.,"the chance of winning more money increased"), and of these subjects, $67 \%$ (35 of 52) acted consistently with the predicted behavior when using the strict criterion, and $75 \%$ (39 of 52) did so when using the weak criterion. Only $20 \%$ (4 of 20) of the other subjects did so as measured strictly; only 40\% ( 8 of 20 ) did so when measured weakly. This is not a perfect measure of comprehension for many reasons. ${ }^{14}$ Nonetheless, it suggests that understanding the strategic setting led subjects to increase their flipping as the continuation probability increased. Indeed, no other characteristic, such as sex, exposure to statistics, and so on, seems to better predict their behavior; comprehension of the strategic environment best predicts whether or not a subject acted in accordance with our hypothesis. Altogether, this evidence suggests that a large majority of the subjects understood the basic "shadow of the future" logic, and this logic guided their behavior in the predicted manner.

\section{Conclusion}

We have argued and shown experimentally that a longer shadow of the future induces more conflict and less settlement. It is important to reiterate the conditions under which this effect can be expected to occur, both in order to be cognizant of the settings to which

\footnotetext{
${ }^{13}$ We note that these other choice patterns need not be classified as irrational. For example, a subject who cares about payoff equity and not her own payoff would choose split under each of the treatment values for $p$; an extremely risk averse subject would also choose split under each value for $p$; a very risk-loving subject who disliked extreme inequity might flip under $p=0$ but not $p=0.5$ or $p=0.75$; and a subject who wants a high expected payoff so long as it was not too inequitable might flip under $p=0.5$ but not under $p=0.75$ or $p=0$.

${ }^{14}$ Clearly not all subjects who said they were more likely to flip under the higher continuation probability did so. The question was asked after subjects completed their choices and had time to consider an optimal strategy. The very asking of the question may have prompted an answer more indicative of what the subject thought the experimenter wanted to hear.
} 
it applies and for possibly furthering understanding about the determinants of peace and conflict more generally. One condition for the effect to occur is that open conflict changes the future strategic positions of the adversaries differently than settlement (in the shadow of conflict) does. This condition is satisfied in many war, litigation, and other conflictual settings and is clearly empirically relevant.

The other condition under which the effect holds is that contracts on an enforcement variable like arming or litigation expenditures are not enforceable. That is, contracts can only be self-enforced through the choices on the enforcement variables made by the adversaries or that settlements only occur under the threat of conflict. This condition also appears to apply in many conflictual settings. For situations that may involve actual warfare, the condition implies a level of absence of trust (or, equivalently of institutions of governance) between the adversaries that at best may lead to a protracted Cold War, which in our models would be represented by a series of settlements. Whether hot or cold, such wars are expensive, the former in terms of arming and destruction, the latter in terms of arming. Then, reducing the expense as well as the likelihood of war would amount to developing the trust or the institutions of governance that would make long term contracts on arming easier to enforce.

One way that trust could emerge has been extensively studied theoretically: through supergame strategies following the folk theorem. However, trust may be too elusive to achieve in many economic and political settings. Actual institutions of conflict management and of governance - independent courts and bureaucracies, checks and balances, other third parties - may be necessary to enforce long-term agreements. Such institutions are costly and take time to build, and as in the case of folk theorem settings we expect a longer value attached to the future to increase the incentives to invest in such costly institutions (for such model, see Genicot and Skaperdas, 2002, and Gradstein, 2004). That is, the settings and the effect of the shadow of the future - that we have examined in this paper involve the absence of "property rights" that may be due to the absence of trust or institutions. Building such property rights would be more likely in conditions in which the future is highly valued. 
Thus, embedding the types of models we have examined here within more-encompassing ones that involve the endogenous emergence of trust and institutions would be a natural next step, both as means to further clarifying the effect of the shadow of the future and for improving understanding of why conflict occurs.

\section{APPENDIX}

\section{A Endogenous Enforcement}

In this Appendix we present an extension of the model from Section 3 to allow for endogenous enforcement levels. It is a dynamic contest model that draws on McBride and Skaperdas (2007). Contest models have been applied in cases of war, litigation, rent-seeking and other settings (see Konrad, 2009, for an overview of the contests literature). The main comparative static result regarding the effect of the shadow of the future is shown to hold in this setting.

To allow for endogenous enforcement, we first need to specify how probabilities of winning depend on enforcement. We suppose that these probabilities depend on arming through the following additive contest success function (see Tullock, 1980, Hirshleifer, 1989, Clark and Riis, 1998):

$$
q_{i}\left(e_{A}, e_{B}\right)=\frac{e_{i}^{m}}{e_{A}^{m}+e_{B}^{m}} \text { where } i=A, B \text { and } m \in(0,1] .
$$

In each period, the sequence of moves by the two sides is the following:

1. Levels of enforcement, $e_{A}$ and $e_{B}$, are chosen simultaneously by the two agents.

2. The two agents bargain. Agent $A$ offers a division (subsidy) $S$ of the period's surplus to $B$. If $B$ accepts, then agent $B$ receives $S$, agent $A$ receives $Y-S$, and the next period repeats steps 1 and 2 . If $B$ rejects the offer, Conflict occurs with winner selected according to probabilities $q_{A}$ and $q_{B}$. The winner receives $\phi Y$ for the period and $Y$ in each period thereafter, whereas the loser receives 0 for the period and thereafter.

Note that when agent $A$ contemplates whether to offer a subsidy to agent $B$ or decide to engage in Conflict, the continuation payoff of agent $B$ would still be the one described in 
(2). Conditional on Settlement, the subsidy that would just induce $B$ not to go to Conflict is the following variation of (4):

$$
S^{*}\left(e_{A}, e_{B}\right)=q_{B}\left(e_{A}, e_{B}\right)[\phi(1-p)+p] Y+p e_{B}
$$

This subsidy is derived under the condition that the same level of enforcement, $\left(e_{A}, e_{B}\right)$, would be chosen in every future period as well as in the current period. Note how this subsidy to agent $B$ depends on its probability of winning, which is increasing in the enforcement level of the agent, as well as directly on the enforcement level of the agent, for under Settlement the agent would have to incur this cost of enforcement in every period.

The payoffs of the two agents under Settlement can now be calculated. Agent $A$ would receive in every period the total surplus minus the subsidy, $Y-S^{*}=Y-q_{B}\left(e_{A}, e_{B}\right)[\phi(1-$ $p)+p] Y-p e_{B}$, whereas in every period it would pay the cost of enforcement, $e_{A}$. We denote by $\left(e_{A}^{P}, e_{B}^{P}\right)$ the future levels of enforcement as part of a Markov perfect equilibrium, whereas the choices in the current period are denoted by $\left(e_{A}, e_{B}\right)$. Then, agent $A$ 's payoff is as follows

$$
V_{A}^{P}\left(e_{A}, e_{B}\right)=\frac{1}{1-p}\left\{Y-q_{B}\left(e_{A}, e_{B}\right)[\phi(1-p)+p] Y-p e_{B}^{P}-p e_{A}^{P}\right\}-e_{A} .
$$

Agent $A$ receives subsidy $S^{*}=q_{B}\left(e_{A}, e_{B}\right)[\phi(1-p)+p] Y+p e_{B}$ in every period and pays the cost of arming $\left(e_{B}\right)$ in every period as well. Then, agent $B$ 's payoff reduces to

$$
V_{B}^{P}\left(e_{A}^{P}, e_{B}^{P}\right)=\frac{1}{1-p}\left\{q_{B}\left(e_{A}, e_{B}\right)[\phi(1-p)+p] Y\right\}-e_{B}
$$

The payoffs are not symmetric because $A$ is always the proposer and the subsidy offered is just the one that equates $B$ 's Settlement payoff with his expected payoff under Conflict.

The Markov perfect equilibrium strategies under Settlement are such that $e_{A}^{P}$ maximizes $V_{A}^{P}\left(e_{A}, e_{B}^{P}\right)$ whereas $e_{B}^{P}$ maximizes $V_{B}^{P}\left(e_{A}^{P}, e_{B}\right)$. To solve for these equilibrium strategies, first differentiate to obtain the first order conditions $\frac{\partial V_{A}^{p}}{\partial e_{A}}=0$ and $\frac{\partial V_{B}^{p}}{\partial e_{B}}=0$. Next, use

$$
\frac{\partial q_{B}}{\partial e_{A}}=\frac{-m e_{A}^{m-1} e_{B}^{m}}{\left(e_{A}^{m}+e_{B}^{m}\right)^{2}}, \frac{\partial q_{B}}{\partial e_{B}}=\frac{m e_{A}^{m} e_{B}^{m-1}}{\left(e_{A}^{m}+e_{B}^{m}\right)^{2}} .
$$

obtained from (7) and the first order conditions to show that

$$
e_{A}^{P}=e_{B}^{P}=\frac{m}{4} \frac{(\phi(1-p)+p)}{(1-p)} Y
$$


Both sides choose the same level of arming despite the asymmetry of payoffs in (9) and (10) because the cost of arming is the same and what becomes effectively contestable is the discounted total surplus under Conflict $\left(\frac{(\phi(1-p)+p)}{(1-p)} Y\right)$.

Note the strong positive dependence of enforcement on the discount factor through the effect of the discounted total surplus under Conflict $\left(\frac{(\phi(1-p)+p)}{(1-p)} Y\right)$. For example, supposing $\phi=0.5$, an increase in the discount factor from 0.9 to 0.95 more than doubles the term $\frac{(\phi(1-p)+p)}{(1-p)}$ from 9.5 to 19.5. As we've seen in section 3 (see (6)), a higher discount factor, as well higher levels of (fixed) arming, increases the likelihood of Conflict. With endogenous enforcement levels, a higher discount factor increases equilibrium enforcement, and the set of parameters for which Conflict becomes an equilibrium must increase compared to the case with exogenous enforcement.

Before deriving such a set of parameters, we consider the case of Conflict. The payoffs under Conflict are the following:

$$
V_{i}^{W}\left(e_{A}, e_{B}\right)=q_{i}\left(e_{A}, e_{B}\right) \frac{(\phi(1-p)+p)}{(1-p)} Y-e_{i}, i=A, B .
$$

It is straightforward to show that equilibrium enforcement is not just symmetric but the same as under Settlement:

$$
e_{A}^{C}=e_{B}^{C}=\frac{m}{4} \frac{(\phi(1-p)+p)}{(1-p)} Y=e_{i}^{S}, i \in A, B .
$$

The reason for the identical levels of enforcement under both Settlement and Conflict is that, even under Settlement, the determinant of equilibrium enforcement is the payoff under Conflict, and the latter determines the disagreement point in bargaining for the two sides. Under both Settlement and Conflict the relevant portion of $B$ 's payoff that can be influenced by its choice of arming is $q_{B}\left(e_{A}, e_{B}\right) \frac{(\phi(1-p)+p)}{(1-p)} Y$, whereas for $A$ it is either $-q_{B}\left(e_{A}, e_{B}\right) \frac{(\phi(1-p)+p)}{(1-p)} Y$ (for the case of Settlement) or $q_{A}\left(e_{A}, e_{B}\right) \frac{(\phi(1-p)+p)}{(1-p)} Y$ (for the case of Conflict) which equals $\left(1-q_{B}\left(e_{A}, e_{B}\right) \frac{(\phi(1-p)+p)}{(1-p)} Y\right.$, both of which leads to the same marginal incentives in the choice of enforcement. 
The set of parameters under which either Settlement or Conflict prevail can be derived by substituting the endogenous enforcement levels from (14) or (6). Settlement occurs when

$$
\frac{p m(\phi(1-p)+p)}{2(1-p)^{2}(1-\phi)} \leq 1 .
$$

From (15) we conclude that Conflict is more likely and Settlement less likely when (i) the effectiveness of conflict as represented by $m$ is high; (ii) the higher is the discount factor $p$; and (iii) the less destructive Conflict is (or, the higher is $\phi$ ). The effect of the discount factor is, if anything, stronger here because as we mentioned above a higher discount factor not only increases the discounted value of the future cost of arming under Settlement but also increases the equilibrium level of arming.

\section{B An Alternative Litigation Setting}

The models of section 3 and Appendix A could be interpreted as involving two parties that are involved in a long-term legal but potentially decisive dispute. For example, they might have competing claims on a productive asset which they can exploit jointly under a series of short-term agreements (that is, under the Settlement outcome), backed by their respective litigation expenditures, or they could resolve once-and-for-all in court (under the Conflict outcome). In this Appendix, we examine a variation of the model of section 3 with one longterm agent potentially facing a series of short-term agent who could sue the long-term agent for damages. The main purpose of this model is to show how the main comparative-static result of the effect of the shadow of the future readily extends to such settings.

Consider a long-term agent $A$, with an indefinite horizon, who faces in each period a short-term potential challenger $b$ (each lasting one period) who could sue agent $A$ for the rights to a one-time payment of $Y$. To sue $A$ a challenger would have to incur a fixed cost of $e_{b}>0$. If no court decision has taken place in the past, let $q_{o}$ denote the probability of winning in court of agent $A$, with $1-q_{o}$ thus representing the challenger's probability of winning. We suppose that $q_{o} \geq 1 / 2$ (so that $A$ can be thought of as having a better initial 
property right than the challengers. If sued, agent $A$ incurs a legal cost $e_{A}>0$ regardless of whether the two sides go to court or not; this cost can be thought of as the cost of hiring a legal team that would help $A$ with the possible settlement and pre-trial costs but also preparing for the eventuality of going to court. If the two sides were to go to court, both would incur an additional cost $c>0$.

As in the model of section 1, $A$ can make a Settlement offer to $b$, which the latter accepts or rejects. Once $b$ has sued (and has paid cost $e_{b}$ ), his expected payoff of going to court is

$$
U_{b}^{c}\left(q_{o}\right)=\left(1-q_{o}\right) Y-c
$$

$A$ could offer a payment $S_{o}=\left(1-q_{o}\right) Y-c$ to $b$, which $b$ could accept, and thus settle or she could offer something less, which $b$ would reject, resulting in the two sides going to court. Let us now consider what could occur under the two possibilities.

First, if $A$ were to make the payment $S_{o}$ and then continue doing so to each future challenger, her payoff would be $\mathrm{e}^{15}$

$$
\begin{aligned}
V_{A}^{s}\left(q_{o}\right) & =Y-S_{o}+\sum_{t=1}^{\infty} p^{t}\left(Y-S_{o}-e_{A}\right) \\
& =q_{o} Y+c+\sum_{t=1}^{\infty} p^{t}\left(q_{o} Y+c-e_{A}\right)=\frac{q_{o} Y+c-p e_{A}}{1-p} .
\end{aligned}
$$

Note that for the challenger in each period to choose to sue, it must be the case that the settlement payment received from $A$ is higher than the cost of suing, or

$$
S_{o}=\left(1-q_{o}\right) Y-c \geq e_{b}
$$

We suppose that this condition is satisfied for the remainder of this Appendix.

Going to court yields more complicated long-term outcomes. If the court decides in favor of $A$, then all future challengers $b$ face worse odds of winning in the future. Let $q_{h}\left(>q_{o}\right)$ denote $A$ 's future probability winning in court in the future. Conversely, if $A$ loses in court following an initial challenge, her future probability of winning decreases to $q_{l}\left(<q_{o}\right)$. To

\footnotetext{
${ }^{15}$ Note that this value does not include the cost of $e_{A}$ which is considered to have been already paid. We continue the same practice in denoting values functions net of this cost below.
} 
determine the expected payoffs of going to court, we thus need to determine the expected payoffs in the case of a court win and and in the case of a court loss.

Suppose that in the case of a win, $A$ would not be challenged in the future. (This could be assured if $e_{b}>\left(1-q_{h}\right) Y-c$, the latter being the expected payoff of a challenger. $)^{16}$ Then, the value of having a probability of winning of $q_{h}$ from next period onward would be $\frac{Y}{1-p}$.

In the case of a loss, there will always be a challenge given that $\left(1-q_{l}\right) Y-c>\left(1-q_{o}\right) Y-c$ which by assumption is greater or equal than $e_{b}$. Then, there is the possibility of settlement and that of going to court, again, in that case. Suppose first the case of settlement. Each challenger $b$ would receive in each period a settlement payment $S_{l}=\left(1-q_{l}\right) Y-c$, with the expected payoff of $A$, denoted $V_{B}^{s}\left(q_{l}\right)=\frac{Y-S_{l}-e_{A}}{1-p}=\frac{q_{l} Y+c-e_{A}}{1-p}$. Therefore, if there is settlement when $A$ loses after going to court the first time, the expected payoff of going to court is

$$
V_{A}^{C s}\left(q_{o}\right)=q_{o} Y-c+q_{o} p \frac{Y}{1-p}+\left(1-q_{o}\right) p \frac{q_{l} Y+c-e_{A}}{1-p} .
$$

In that case, $A$ will choose to go to Court if and only if ${ }^{17}$

$$
\begin{aligned}
V_{A}^{s}\left(q_{o}\right) & <V_{A}^{C s}\left(q_{o}\right) \Rightarrow \\
\frac{q_{o} Y+c-p e_{A}}{1-p} & <q_{o} Y-c+q_{o} p \frac{Y}{1-p}+\left(1-q_{o}\right) p \frac{q_{l} Y+c-e_{A}}{1-p} \Rightarrow \\
\left(2-p\left(2-q_{o}\right)\right) c & <p\left(1-q_{o}\right) q_{l} Y+q_{o} e_{A} .
\end{aligned}
$$

Because both sides of this inequality are positive, the range of parameters that would result in going to court is larger the higher is $p$. In other words, the effect of the shadow of the future holds in this setting, a setting that involves less decisive conflict than that of the models in section 3 and appendix A. We also note, but do not have space to show formally here, that the effect remains under still richer variations of this setting. For example, if $A$ 's win probability, once it drops after a loss may later rise again after a win, then the shadow of the future effect still operates. We thus see that the shadow of the future looms large across many settings.

\footnotetext{
${ }^{16}$ If there were to be future challenges, similar results would be obtained.

${ }^{17}$ We suppose that Settlement occurs when the two payoffs are equal.
} 


\section{References}

[1] Abbink, Klaus and Jordi Brandts, 2009, "Political Autonomy and Independence: Theory and Experimental Evidence," working paper, January.

[2] Axelrod, Robert, 1984, The Evolution of Cooperation, New York: Basic Books.

[3] Bacharach, Michael, 2006, Beyond Individual Choice: Teams and Frames in Game Theory, Princeton: Princeton University Press.

[4] Bester, Helmut and Kai Konrad, 2004, "Delay in Contests," European Economic Review 48 (5), 1169-1178.

[5] Bester, Helmut and Karl Warneryd, 2006. "Conflict and the Social Contract," Scandinavian Journal of Economics, 108(2), 231-249.

[6] Blattman, Christopher and Edward Miguel, 2009, "Civil War," Journal of Economic Literature, forthcoming.

[7] Blomberg, Brock and Gregory D. Hess, 2008, "The Welfare Cost of Conflict," Claremont McKenna College.

[8] Brito, Dagobert and Michael Intriligator, 1985, "Conflict, War and Redistribution," American Political Science Review, 79 (4), 943-957.

[9] Buchanan, James, 1989, Notes on Irrelevant Externalities, Enforcement Costs, and the Atrophy of Property Rights. In: Tollison, R. and Vanberg, V. (eds) Explorations Into Constitutional Economics. College Station: Texas A\&M University Press.

[10] Clark, Derek. and Christian Riis, 1998, "Contest Success Functions: An Extension," Economic Theory, 11, 201-204.

[11] Collier, Paul, Elliott V.L., Hegre Havard, Hoeffler, Anke, Reynal-Querol, Marta, and Sambanis, Nicholas, Breaking the Conflict Trap; Civil War and Development Policy, (World Bank Policy Report), 2003, Washington, DC: World Bank and Oxford University Press.

[12] Dal Bó, Pedro, 2005, "Cooperation under the Shadow of the Future: Experimental Evidence from Infinitely Repeated Games," American Economic Review, 95 (5), 15911604. 
[13] Durham, Yvonne, Jack Hirshleifer, and Vernon L. Smith, 1998. "Do the Rich Get Richer and the Poor Poorer? Experimental Tests of a Model of Power," American Economic Review, September, 88(4), 970-83.

[14] Esteban, Joan and Debraj Ray,1999. "Conflict and Distribution," Journal of Economic Theory, 87(2), 379-415.

[15] Esteban, Joan and Debraj Ray, 2008, "On the Salience of Ethnic Conflict," American Economic Review, December, 98(5), 2185-2202.

[16] Farmer, Amy and Pecorino, Paul, 1999, "Legal Expenditure as a Rent Seeking Game", Public Choice, September, 100, 271-288.

[17] Fearon, James, 1995, "Rationalist Explanations for War," International Organization, 49(3), 379-414.

[18] Garfinkel, Michelle and Stergios Skaperdas, 2000, "Conflict Without Misperception or Incomplete Information: How the Future Matters," Journal of Conflict Resolution, 44(6), 793-807.

[19] Genicot, Garance and Stergios Skaperdas, 2002, "Investing in Conflict Management," Journal of Conflict Resolution, 46, 154-170.

[20] Gradstein, Mark, 2004, "Governance and Growth," Journal of Development Economics, $73,505-518$.

[21] Green, Edward J and Robert H. Porter, 1984, "Noncooperative collusion under imperfect price information," Econometrica, 52(1), 87-100.

[22] Greif, Avner, 2006, Institutions and the Path to the Modern Economy: Lessons from Medieval Trade, New York: Cambridge University Press.

[23] Grossman, Sanford and Oliver Hart, 1986, "The Costs and Benefits of Ownership: A Theory of Vertical and Lateral Integration," Journal of Political Economy, 84, 691719 .

[24] Hay, B. and Spier, K, 1998 Settlement of Litigation. In: Newman, P. (ed.) The New Palgrave Dictionary of Economics and the Law, New York: Stockton Press.

[25] Hirshleifer, Jack, 1989, "Conflict and Rent-seeking Success Functions: Ratio Vs. Difference Models Of Relative Success." Public Choice, 63(2), 101-12. 
[26] Hirshleifer, Jack, 1991, "The Paradox of Power," Economics and Politics, 3(3), 177200.

[27] Hirshleifer, Jack and Evan Osborne, 2001, "Truth, Effort and the Legal Battle", Public Choice, 108, 169-195.

[28] Jackson, Matthew O. and Massimo Morelli, 2008, "Strategic Militarization, Deterrence and Wars," September, working paper.

[29] Joll, James, 1992, The Origins of the First World War, 2nd Edition, New York: Longman.

[30] Konrad, Kai A., 2009, Strategy and Dynamics in Contests, New York: Oxford University Press.

[31] Mailath, George J. and Larry Samuelson, 2006, Repeated games and reputations: long-run relationships, Oxford: Oxford University Press.

[32] McBride, Michael and Stergios Skaperdas, 2007, "Explaining Conflict in LowIncome Countries: Incomplete Contracting in the Shadow of the Future," in M. Gradstein and K.A. Konrad, (eds.), Institutions and Norms in Economic Development, 141161, Cambridge, MA: MIT Press.

[33] McNeill, William, 1982, The Pursuit of Power, Chicago: University of Chicago Press.

[34] Mehlum, Halvor and Karl Moene, 2006, "Fighting Against the Odds," Economics of Governance, 7(1), 75-8.

[35] Powell, Robert, 1993, "Guns, Butter, and Anarchy," American Political Science Review, March, 87(1), 115-132.

[36] Powell, Robert, 2006, "War as a Commitment Problem," International Organization, 60, 169-203.

[37] Richardson, Gary and Michael McBride, 2009, "Religion, longevity, and cooperation: The case of the craft guild," Journal of Economic Behavior and Organization, forthcoming.

[38] Robson, Alexander and Skaperdas, Stergios, 2008, "Costly Enforcement of Property Rights and the Coase Theorem," Economic Theory, July, 36(1), 109-128.

[39] SIPRI (Stockholm International Peace Research Institute), 2008, Armaments, Disarmament and International Security, Summary, Stockholm. 
[40] Skaperdas, Stergios, 2006, "Bargaining vs. Fighting," Defense and Peace Economics, December, 17(6), 657-676.

[41] Skaperdas, Stergios and Constantinos Syropoulos, 1996, "Can the Shadow of the Future Harm Cooperation," Journal of Economic Behavior and Organization, 29, 355372.

[42] Tingley, Dustin H., 2009, "The Dark Side of the Future: An Experimental Test of Commitment Problems in Bargaining," manuscript, Princeton University, Department of Political Science.

[43] Tullock, Gordon, 1980, "Efficient Rent Seeking." In Toward a Theory of the Rent Seeking Society, edited by James M. Buchanan, Robert D. Tollison, and Gordon Tullock, College Station: Texas A\&M University Press, 3-15. 


\section{SUPPLEMENTAL APPENDIX NOT FOR PUBLICATION}

\section{Experiment Dialogue}

\section{Introduction}

Welcome to the California Social Science Experimental Laboratory. This experiment is being conducted by

You are about to participate in a session on decision-making, and you will be paid for your participation in cash, privately at the end of the session. What you earn depends partly on your decisions, partly on the decisions of others, and partly on chance.

Please turn off pagers and cellular phones now. Please close any program you may have open on the computer.

The entire session will take place through computer terminals, and all interaction between you will take place through the computers. It is important that you not talk or in any way try to communicate with other participants during the session.

We will start with a brief instruction period. During the instruction period you will be given a description of the main features of the session and will be shown how to use the computers. If you have any questions during this period, raise your hand and your question will be answered so everyone can hear. This experiment is expected to take between 60 and 75 minutes.

\section{General Instructions}

After a brief instructional period, you will participate in _ _ practice matches, __ real matches, and then a wrap-up. At the end of the wrap-up, you will be paid the total amount you have accumulated during the course of the real matches in addition to the show-up fee. Everybody will be paid in private after showing the record sheet. You are under no obligation to tell others how much you received.

During the session all the earnings are denominated in points. Your dollar earnings at the end of the session are determined by the points-dollar exchange rate posted on the board in the front of the room. This exchange rate is _ _ point equals _ _ out to ___ points per dollar.

The participants are divided in two groups: Red and Blue. Red participants will be matched with blue participants, and vice versa. A Red is never matched with a Red, and a Blue is never matched with a Blue. These color designations are only used for matching participants.

You and the person with whom you are matched must determine how to allocate a stream of points between the two of you. The size of the stream of points depends on the number of rounds you interact with you matched participant. The more rounds, the larger the stream of points. The exact number of rounds in your match is determined randomly, as described in a moment.

Either you will split the stream of points equally in each round, or you will have the computer flip a coin to determine whether you receive all the points in all rounds or whether the participant with whom you are matched receives all the points. You must also pay fees 
based on the way the points are allocated. If you split the points, then both you and your matched participant must pay a standard fee in each round. If the coin flip determines who receives the points, then each person must pay the standard fee only in round 1 of your interaction. The recipient also pays an additional flipping fee in the first round. In all following rounds following a flip, no fees are paid. I will describe these points in more detail below.

Whether you split the points or have a coin flip determine the recipient depends on choices made by you and the person with whom you are matched. If you both want to split, then you will split the points equally. If one or both of you want the flip to decide, then the coin flip determines the recipient. This coin flip is fair; you and your matched participant are equally likely to receive the points.

This session will use the following points. In each round, there are 100 points to allocate. The standard fee is 30 , and the flipping fee is 30 . This means that if you split the points, then in each round of your match, you will receive $50-30=20$ points. If a flip determines the recipient, the recipient receives $100-30-30=40$ in round 1 and 100 in every round of the match after that. The non-recipient receives -30 in round 1 and 0 in every other round of the match. This point information will be visible on your computer screen throughout the session.

The exact number of rounds is determined randomly by the computer according to the continuation probability. The continuation probability is the probability that the match continues to round 2 , the probability that round 3 is reached given you are in round 2 , and so on. We will use three continuation probabilities today: $0.75,0.5$, and 0 . You will be told the continuation probability at the start of each match.

Consider the following example. Suppose the continuation probability is 0 . Because there is a $0 \%$ chance of your match continuing to round 2 , it means that your match will last only 1 round. This means that if you both choose to split, then you each receive 20, and your match ends. If a flip determines the recipient, the recipient receives 40, the non-recipient pays 30 , and the match ends.

Now suppose the continuation probability is 0.5 . Now there is a $50 \%$ chance that the match continues to round 1 , a $50 \%$ chance that the match continues to round 3 if round 2 was reached, a $50 \%$ chance that the match continues to round 4 if round 3 was reached, and so on. If you both choose split, you each receive 20 points in each round of your match. If a flip determines the recipient, the recipient receives 40 in round 1 and 100 in any round thereafter should any other round be reached, and the non-recipient receives -30 in round 1 and 0 in any round that is reached thereafter.

If the continuation probability is 0.75 , the possible payments are similar to the 0.5 continuation probability case except there is now a larger chance that later rounds will be reached.

Throughout the session, your computer screen will display the appropriate payment table as a reminder of how the points are allocated. 
Any questions?

\section{Practice Rounds}

We will begin the practice matches now. During the practice match do not hit any keys or click the mouse until you are told to do so. You are not paid for the practice match; it is just for you to familiarize yourself with the session and the computer program.

At this time, please pull out the dividers that separate you from your neighbors. During the course of this session, please refrain from communicating with your neighbors.

In a moment, I will ask you to double click on one of the icons on your screen. When you do this, please double click only once. There may be a delay after you click, so please double-click only once. OK, please double click on the ___ icon now. Then wait...

In the dialog box, please enter what is on the sticker at the top of your monitor. For example, if it says SSEL93, please enter SSEL93.

In each match every Red participant is paired with a Blue participant. You will not be paired twice with the same participant during the session or with a participant that was paired with someone that was paired with you or with someone that was paired with someone that was paired with someone that was paired with you, and so on. Thus, the pairing is done in such a way that the decisions you make in one match cannot affect the decisions of the participants you will be paired with in later matches or later parts of the session.

You should now see on your screen the computer interface. It should look like the image displayed at the front of the room.

The upper right lists your computer ID number which has been assigned by the computer. It also lists which group you have been assigned for the practice matches, either Blue or Red. Finally, it lists the exchange rate, the total points, and the total dollar amount equivalent of those points. The show-up payment _ _ will be added to this total at the end of the real rounds of the session when we calculate your final take home amount.

Notice that it says you currently have ___ points. This is an initial amount for you to use when making your selections. As the session practice matches progress, you will add to this amount or pay out of it depending on the selections made by you and your matched participant and by the computer.

The computer has now matched you with another individual in the room. If you are Blue, you have been matched with a Red, and vice versa. The bottom half of the screen displays the history of your interactions. The first column of your history shows that you are now in the first round of this particular match. The second column tells you that there are 100 points per round to be allocated. The third column tells you that the continuation probability is 0 . The fourth and fifth columns tell you that the standard and flipping fees are each 30 .

The upper left shows the points diagram that corresponds to this match. The upper middle displays the selection area. Your selections in the selection area determine whether the points are split or if the coin flip chooses the recipient.

Your screen shows that you can choose either SPLIT or FLIP. If you both select SPLIT, 
then the points are split evenly between you and your matched participant. If one or both of you select FLIP, then the computer coin flip will determine who receives the points.

After both you and your matched participant make your selections, the computer randomly decides whether the match continues to another round according to the "Continuation Probability."

Let us now do the first practice match to familiarize yourself with the computer interface. Will you please select SPLIT in the selection area and then click CONFIRM to confirm your selection.

Once you and your partner have selected, the computer will calculate your points for this first round. Because the continuation probability is 0 , the match will then end. The results of your round appear in the history box. You should see that your payment for each round is half of 100 minus the standard fee for a total of 20 points.

A dialogue box then appears to notify you when the match has ended. This box also shows the total dollar amount, after adjusting for the exchange rate that you have received. Please close the dialogue box by selecting OK.

Any questions?

We cannot advance to the next match until everybody has closed his or her dialogue box. If you have not done so, please close your dialogue box by selecting OK.

In the second practice match, we will now see what happens when a coin flip determines who receives the points. If you are Blue, please select SPLIT, and if you are Red, please select FLIP. Press CONFIRM.

If you received the points, you should have received 100 minus the standard fee minus the flipping fee for 40 points in round 1. If you did not receive the points, you should have paid the standard fee in round 1 . Because the continuation probability was 0 , the match ended. Please note that the coin flip does not choose a recipient based on which participant selected FLIP. It's choice is independent of who selected FLIP. Please close the dialogue box by selecting $\mathrm{OK}$.

Any questions?

In the third match, the continuation probability is now 0.5 . There is now a $50 \%$ chance that the match continues to a new round. Please choose either FLIP or SPLIT and press CONFIRM now.

The outcome of this match should now be displayed in the history box. The exact points allocated will now depend on the selections made by you and your matched participant, as well as by the computer. The computer now determines randomly whether the match continues. The exact number of matches varies in the room because the computer does a random draw for each matched pair. Thus, for some of you the exact number of rounds was 1 , for others it was 2 , for others it could be $3,4,5$, or more.

Let us now do one final match with continuation probability 0.75 . There is now a $75 \%$ chance that the match continues to a new round.

When your match ends, please close the dialogue box by selecting OK. Please choose 
either FLIP or SPLIT and press CONFIRM now. Observe the outcome of you match in your history box and then please close your dialog box.

We have now finished the practice matches. Any questions?

\section{Part I: Continuation 0}

We will now begin Part I of the real matches. We will reload the software. Please double click the __ icon as before and enter your computer terminal number as before. This is located on the sticker at the top of your monitor. For example, if it says SSEL93, please enter SSEL93. The computer will reassign participants into the Red and Blue groups. Your ID and group assignment may now differ from in the practice matches.

This first part will consist of __ matches. The continuation probability is 0 . That means there is a $0 \%$ chance that you will advance to a new round in your match.

Remember, you will not be paired twice with the same participant during the session. Your decisions in one match cannot affect the decisions of the people you will interact with in future matches. This is not a practice; you will be paid.

You have been given an initial _ _ points. Remember, you will add to or pay out of this amount as the real matches advance.

Make your selection now. Remember to press confirm. When your match ends, press OK. The computer will begin the next match only after all participants have closed the dialogue box. Also please remember to not communicate with any other participants in the room.

Please continue and complete all the matches for Part I.

\section{Part II: Continuation Probability 0.5}

We will now begin Part II of the real matches, which consists of matches. The continuation probability is 0.5 . That means there is a $50 \%$ chance that you will advance to a new round in your match.

Remember, you will not be paired twice with the same participant during the session. Your decisions in one match cannot affect the decisions of the people you will interact with in future matches.

Make your selection now. Remember to press confirm. When your match ends, press OK. The computer will begin the next match only after all participants have closed the dialogue box.

Please continue and complete all the matches for Part II

\section{Part III: Continuation Probability 0.75}

We will now begin Part III of the real matches, which consists of matches. The continuation probability is 0.75 . That means there is a $75 \%$ chance that you will advance to a new round in your match.

Remember, you will not be paired twice with the same participant during the session. Your decisions in one match cannot affect the decisions of the people you will interact with in future matches.

Make your selection now. Remember to press confirm. When your match ends, press OK. The computer will begin the next match only after all participants have closed the dialogue 
box.

Please continue and complete all the matches for Part III.

\section{Experiment Questionnaire}

1. ID number assigned by computer (upper right of screen):

2. Age:

3. Sex (circle one): male female

4. Major/department of study:

5. Type of student (circle one): undergraduate graduate

6. If undergraduate, year in school (circle one): freshman sophomore junior senior

7. Number of economics courses taken?

8. Number of probability, statistics, or econometrics courses taken?

9. How many rounds did you expect a single match to last with continue probability $0.5 ?$

10. How many rounds did you expect a single match to last with continue probability $0.75 ?$

11. Were any parts of the instructions difficult to understand? Any suggestions for improving the instructions?

12. Were you more likely or less likely to select FLIP as the continuation probability increased? Why or why not? 


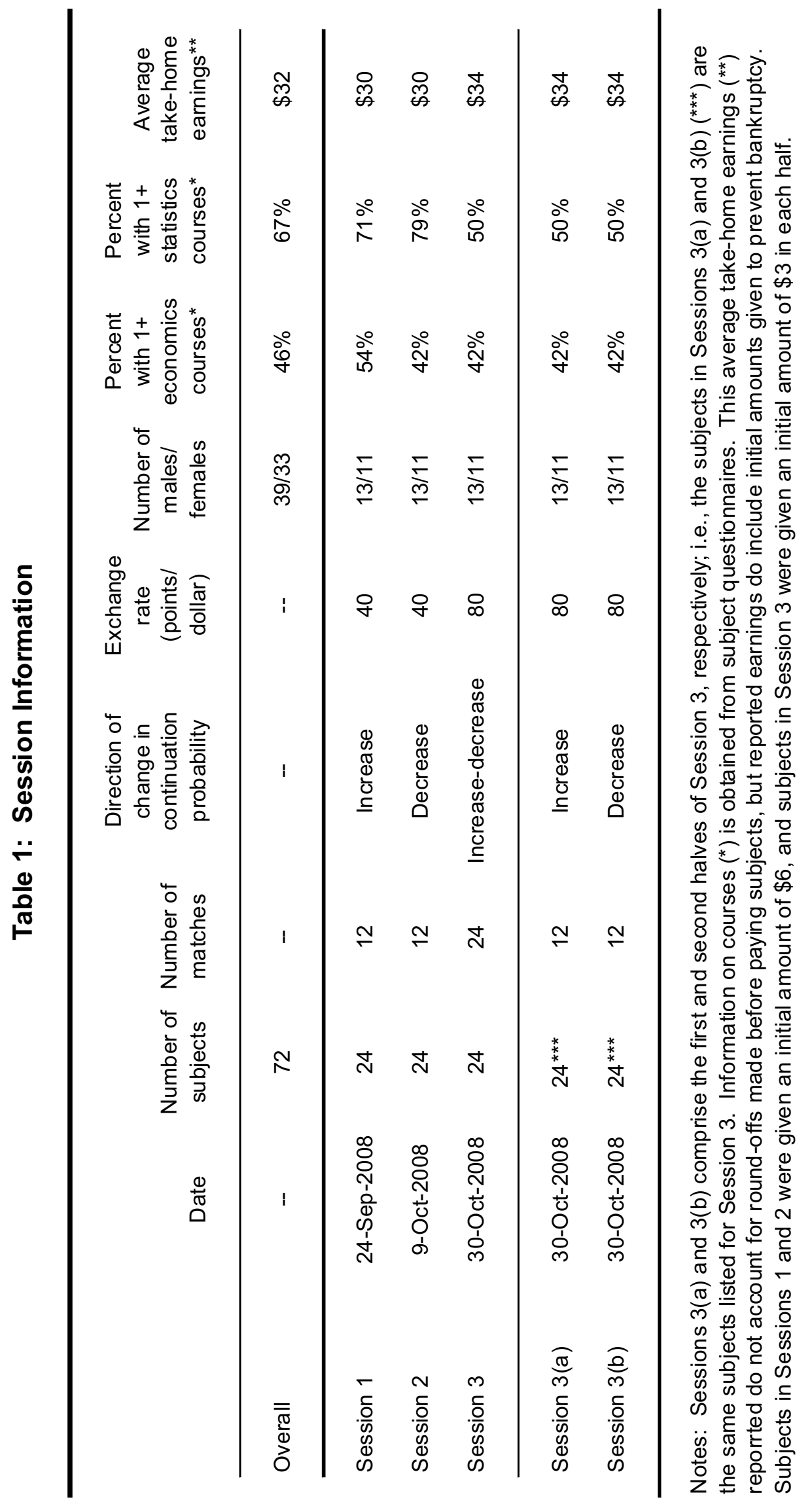



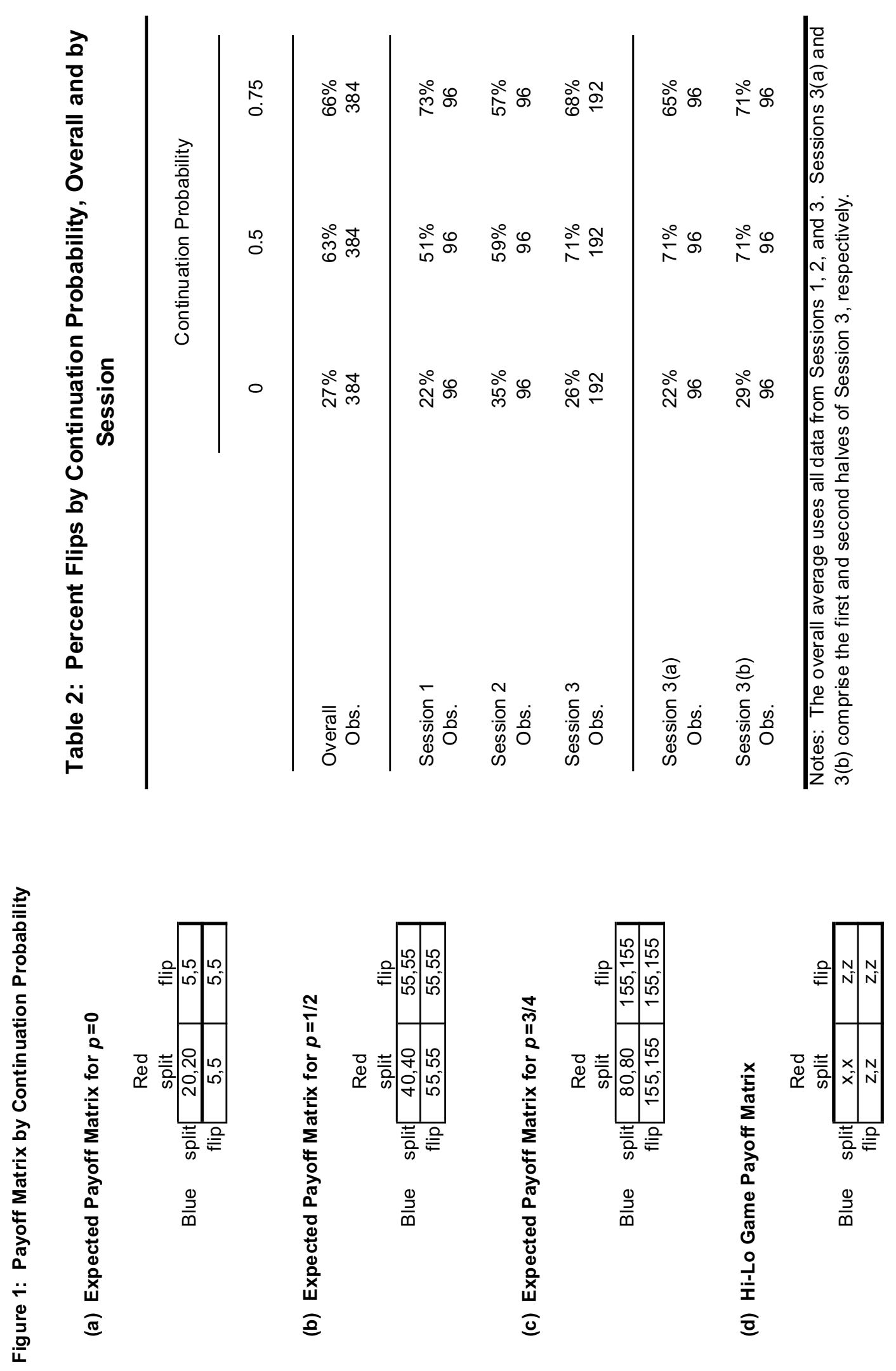
Table 3: Chi-square Test Statistics for Hypothesis 1, Overall and by Session

Hypothesis 1

\begin{tabular}{|c|c|c|c|}
\hline & $\begin{array}{l}1(\mathrm{a}) \\
\text { Proportion of flips } \\
\text { under } p=0 \text { equals } \\
\text { proportion under } \\
\quad p=0.75\end{array}$ & $\begin{array}{l}1(\mathrm{~b}) \\
\text { Proportion of flips } \\
\text { under } p=0 \text { equals } \\
\text { proportion under } \\
\quad p=0.5\end{array}$ & $\begin{array}{c}\text { Proportion of flips } \\
\text { under } p=0.5 \text { equals } \\
\text { proportion under } \\
p=0.75\end{array}$ \\
\hline $\begin{array}{l}\text { Overall } \\
\qquad p \text {-value }\end{array}$ & $\begin{array}{c}119.261 \\
<0.01\end{array}$ & $\begin{array}{c}100.168 \\
<0.01\end{array}$ & $\begin{array}{c}0.964 \\
0.33\end{array}$ \\
\hline $\begin{array}{r}\text { Session } 1 \\
p \text {-value }\end{array}$ & $\begin{array}{l}50.157 \\
<0.01\end{array}$ & $\begin{array}{l}17.626 \\
<0.01\end{array}$ & $\begin{array}{l}9.747 \\
<0.01\end{array}$ \\
\hline $\begin{array}{r}\text { Session } 2 \\
p \text {-value }\end{array}$ & $\begin{array}{l}9.237 \\
<0.01\end{array}$ & $\begin{array}{l}11.051 \\
<0.01\end{array}$ & $\begin{array}{c}0.086 \\
0.79\end{array}$ \\
\hline $\begin{array}{r}\text { Session } 3 \\
p \text {-value }\end{array}$ & $\begin{array}{l}68.659 \\
<0.01\end{array}$ & $\begin{array}{l}78.949 \\
<0.01\end{array}$ & $\begin{array}{c}0.440 \\
0.51\end{array}$ \\
\hline $\begin{array}{c}\text { Session } 3(a) \\
p \text {-value }\end{array}$ & $\begin{array}{l}35.675 \\
<0.01\end{array}$ & $\begin{array}{l}46.267 \\
<0.01\end{array}$ & $\begin{array}{c}0.858 \\
0.35\end{array}$ \\
\hline $\begin{array}{c}\text { Session } 3(b) \\
p \text {-value }\end{array}$ & $\begin{array}{l}33.333 \\
<0.01\end{array}$ & $\begin{array}{l}33.333 \\
<0.01\end{array}$ & $\begin{array}{c}0.000 \\
1.00\end{array}$ \\
\hline
\end{tabular}

Notes: The overall average uses all data from Sessions 1, 2, and 3. 
Figure 2(a): Percent Flips by Match, Session 1

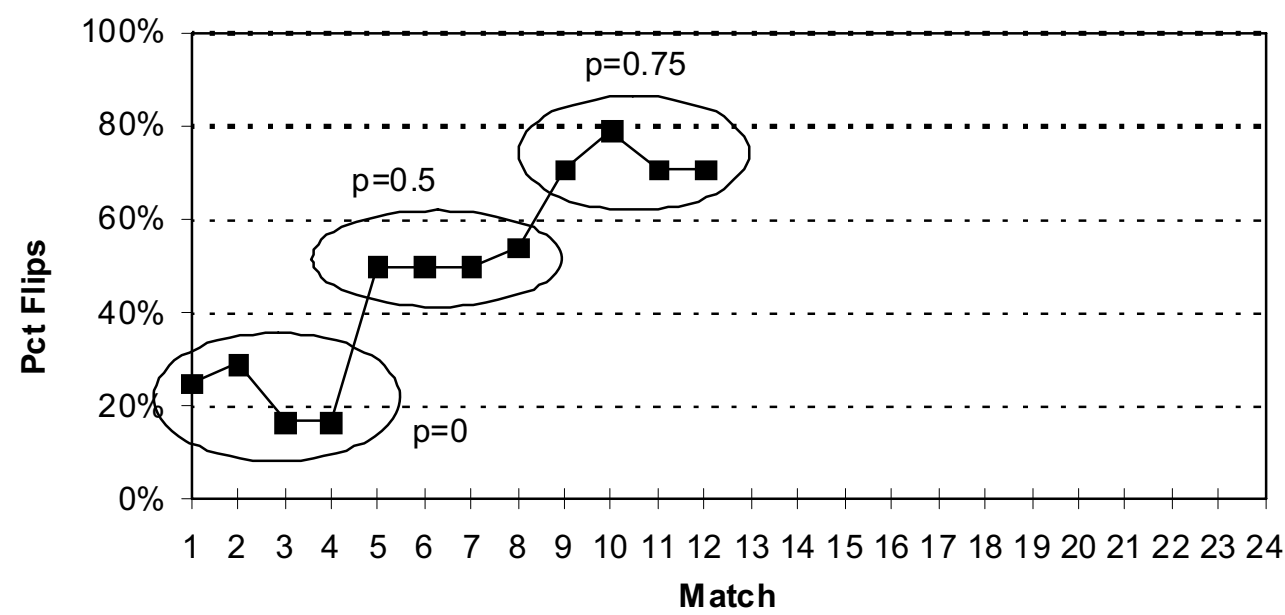

Figure 2(b): Percent Flips by Match, Session 2

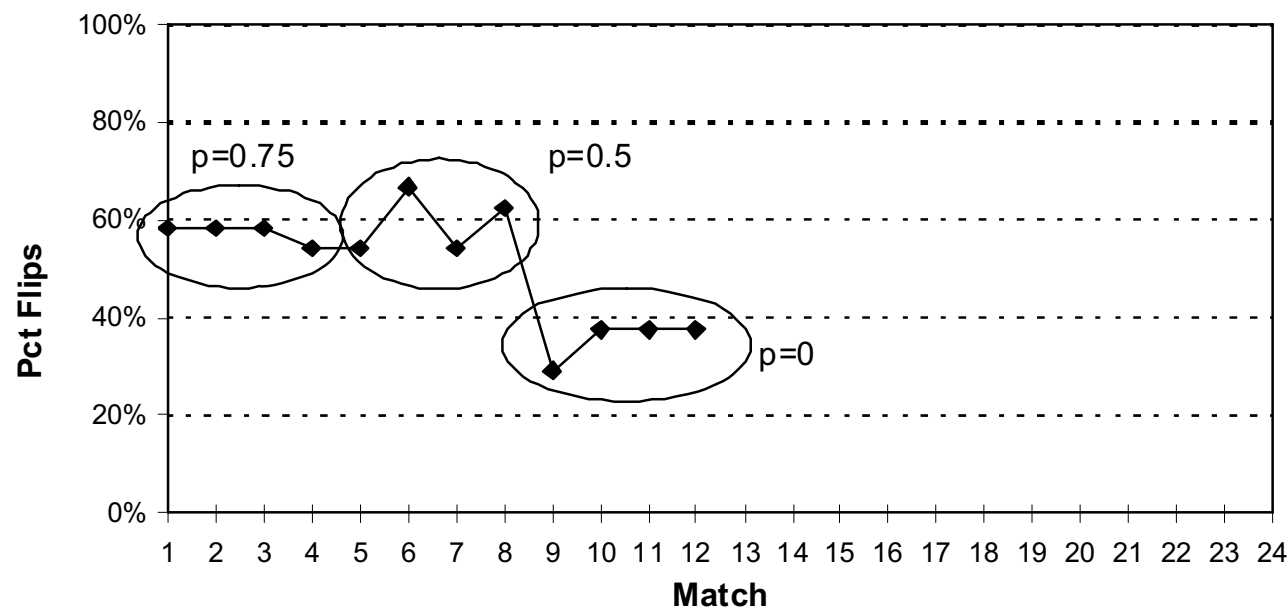

Figure 2(c): Percent Flips by Match, Session 3

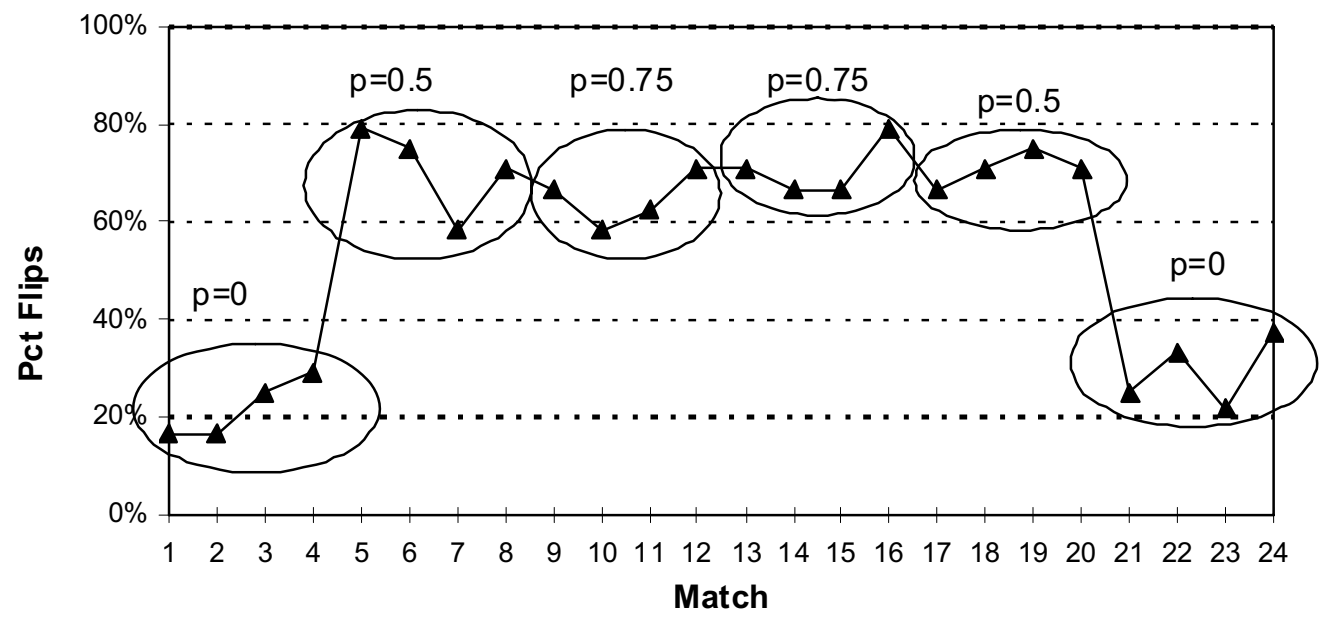


Table 4: Percent Outcomes by Continuation Probability, Overall and by Session

\begin{tabular}{|c|c|c|c|}
\hline & \multicolumn{3}{|c|}{ Continuation Probability } \\
\hline & 0 & 0.5 & 0.75 \\
\hline \multicolumn{4}{|l|}{ Overall } \\
\hline Flip-flip & $5 \%$ & $39 \%$ & $41 \%$ \\
\hline Flip-split & $45 \%$ & $49 \%$ & $51 \%$ \\
\hline Split-split & $51 \%$ & $13 \%$ & $8 \%$ \\
\hline \multicolumn{4}{|l|}{ Session 1} \\
\hline Flip-flip & $0 \%$ & $23 \%$ & $52 \%$ \\
\hline Flip-split & $44 \%$ & $56 \%$ & $42 \%$ \\
\hline Split-split & $56 \%$ & $21 \%$ & $6 \%$ \\
\hline \multicolumn{4}{|l|}{ Session 2} \\
\hline Flip-flip & $8 \%$ & $31 \%$ & $27 \%$ \\
\hline Flip-split & $54 \%$ & $56 \%$ & $60 \%$ \\
\hline Split-split & $38 \%$ & $13 \%$ & $13 \%$ \\
\hline \multicolumn{4}{|l|}{ Session 3} \\
\hline Flip-flip & $5 \%$ & $50 \%$ & $43 \%$ \\
\hline Flip-split & $41 \%$ & $42 \%$ & $50 \%$ \\
\hline Split-split & $54 \%$ & $8 \%$ & $7 \%$ \\
\hline \multicolumn{4}{|l|}{ Session 3(a) } \\
\hline Flip-flip & $4 \%$ & $52 \%$ & $40 \%$ \\
\hline Flip-split & $35 \%$ & $38 \%$ & $50 \%$ \\
\hline Split-split & $60 \%$ & $10 \%$ & $10 \%$ \\
\hline \multicolumn{4}{|l|}{ Session 3(b) } \\
\hline Flip-flip & $6 \%$ & $48 \%$ & $46 \%$ \\
\hline Flip-split & $46 \%$ & $46 \%$ & $50 \%$ \\
\hline Split-split & $48 \%$ & $6 \%$ & $4 \%$ \\
\hline
\end{tabular}




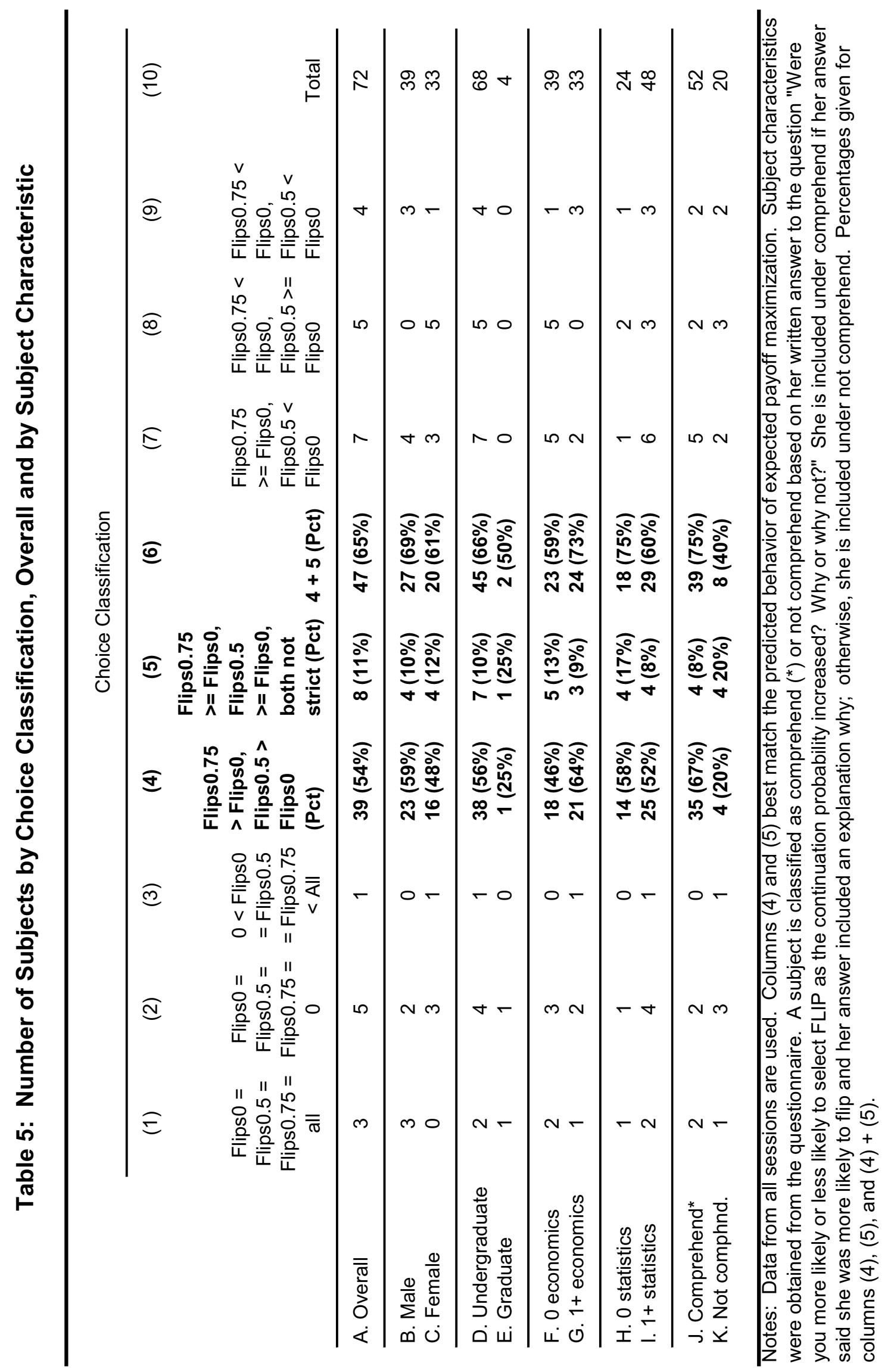

